\title{
Juventude e os desafios do processo de integração ao ambiente universitário: aproximações com a realidade da Faculdade de Educação da Universidade Federal do Amazonas
}

Nádia Maciel Falcão ${ }^{1}$ Margareth Soares Abtibol ${ }^{2}$ Miriane Feitoza dos Santos ${ }^{3}$

\begin{abstract}
Resumo:
Analisa as ações de integração de novos estudantes ao ambiente universitário, desenvolvidas na Faculdade de Educação da Universidade Federal do Amazonas, ancorando-se no debate atual sobre o processo de transição do ensino médio à educação superior no Brasil. A metodologia, de abordagem qualitativa, sustenta-se em referenciais teórico-metodológicos da pesquisa em educação, dialogando com estudos de juventude. Os dados resultam de revisão bibliográfica e análise de documentos. Os resultados apontam que o processo de integração de novos estudantes nos cursos de graduação instigar um debate multidimensional que considere aspectos estruturais que permeiam o contexto de expansão do acesso à educação superior; aspectos institucionais que se expressam em diferentes graus de produção de suporte aos jovens recém ingressos na educação superior; além da indispensável discussão no campo das subjetividades. Na experiência institucional explorada no estudo, observa-se um esforço de integração articulado sobre princípios de deliberação coletiva, participação de diferentes atores e continuidade. Experiência que pode ser favorecida pela inserção de processos de escuta dos jovens.
\end{abstract}

\author{
Palavras-chave: \\ Juventude. Transição. Ensino médio. Educação Superior. Integração.
}

\section{Youth and the challenges of the integration process to the university environment: approximations to the reality of the Faculty of Education at the Federal University of Amazonas}

\footnotetext{
Abstract: This research aims to analyze actions for integration of new students to the university environment, developed at the Faculty of Education of the Federal University of Amazonas, grounded on the current debate about the transition process from secondary to higher education in Brazil. The qualitative

1 Doutora em Educação, Professora do Programa de Pós-Graduação em Educação da Universidade Federal do Amazonas. E-mail: nadiafalcao@ufam.edu.br. ORCID iD: http://orcid.org/0000-0002-3196-0341.

2 Doutoranda em Educação do Programa de Pós-Graduação em Educação da Universidade Federal do Amazonas. E-mail: margareth.abtibol@gmail.com. ORCID iD: http://orcid.org/0000-0002-6013-1454.

3 Licencianda em Pedagogia da Faculdade de Educação da Universidade Federal do Amazonas. E-mail: feitoza.santos1997@gmail.com. ORCID iD: http://orcid.org/0000-0002-5636-5514.
} 
approach methodology is based on theoretical and methodological references of research in education and youth studies. The data is derived from bibliographic review and document analysis. The results show that the process of integrating new students into undergraduate courses instigates a multidimensional debate that considers the structural aspects that permeate the context of expanding access to higher education; the institutional aspects that express themselves in different degrees of production of support for young people newly admitted in higher education; and the indispensable discussion of subjectivities. In this institutional experience, an effort of integration articulated on principles of collective deliberation, participation of different subjects and continuity is observed. Encouraging listening processes of young people can improve this experience.

Keywords: Youth. Transition. Secondary Education. Higher Education. Integration.

\title{
Juventud y los desafíos del proceso de integración al ambiente universitario: Aproximaciones con la realidad de la Facultad de Educación de la Universidad Federal de Amazonas
}

\begin{abstract}
Resumen: Analiza las acciones de integración de nuevos estudiantes al ambiente universitario desarrollado en la Facultad de Educación de la Universidad Federal de Amazonas, apoyándose en el debate actual acerca del proceso de transición de la enseñanza secundaria a la graduación universitaria en Brasil. La investigación de metodología de abordaje cualitativa es basada en referencias teórico-metodológicos de investigación en educación relacionada con estudios de la juventud. Los datos resultan de revisión bibliográfica y análisis de documentos. Los resultados indican que el proceso de integración de nuevos estudiantes en las carreras de graduación ofrece un debate multidimensional que considera las condiciones estructurales que permean el contexto de expansión al acceso a la enseñanza superior, aspectos institucionales que se presentan en distintos grados de producción de suporte a los jóvenes recién ingresos en la enseñanza superior; además, de la indispensable discusión en el campo de las subjetividades. En la experiencia institucional investigada, se nota un esfuerzo de integración articulado en los principios de deliberación colectiva, participación de distintos actores, continuidad de estas acciones y sus efectos. Experiencia que puede ser favorecida por la inserción de los procesos de escucha de los jóvenes.
\end{abstract}

Palabras clave: Juventud. Transición. Enseñanza secundaria. Enseñanza superior. Integración.

\section{Introdução}

O artigo apresenta resultados de pesquisa vinculada ao Programa de Pós-graduação em Educação da Universidade Federal do Amazonas, articulada ao Programa Institucional de Bolsas de Iniciação Científica - PIBIC/UFAM ${ }^{1}$. Dá continuidade a estudos anteriores da temática desenvolvidos sobre a realidade local, os quais evidenciaram a demanda de informações mais qualificadas sobre a universidade por parte dos estudantes do ensino médio e a baixa quantidade e qualidade de suportes ao processo de transição entre ensino médio e educação superior oferecidos no âmbito da educação básica.

Parte do entendimento de que a compreensão do processo de transição requer análises que abarquem também os processos de integração dos jovens na educação superior, justificando-se assim a proposta de analisar ações institucionais voltadas à integração de novos estudantes ao ambiente universitário.

1 Pesquisa desenvolvida com apoio da Coordenação de Aperfeiçoamento de Pessoal de Nível Superior - CAPES e da Fundação de Amparo à Pesquisa do Estado do Amazonas - FAPEAM. 
O século XXI tornou-se, na história da educação brasileira, marco da explosão do acesso ao ensino em todos os níveis. É fato que a novidade do acesso não representa a superação de problemas que se prolongam na agenda pública da educação escolar brasileira, todavia, compreender desdobramentos e efeitos da conquista social, representada pela abertura dos sistemas de ensino aos indivíduos de todas as camadas populares, tem se constituído em um dos principais desafios das ciências da educação na contemporaneidade.

O recorte aqui proposto coaduna-se com esse objetivo mais amplo da área da educação, pois não há como indagar sobre a configuração dos atuais processos de transição entre a educação básica e a educação superior, sem considerar que a própria ideia da continuidade de estudos em nível superior, hoje generalizada entre os concluintes do ensino médio, foi uma construção das últimas três décadas.

Necessário pontuar que a expansão das matrículas na educação superior foi impulsionada principalmente pelo crescimento da iniciativa privada. Conforme explica Barros (2015, p. 363), ainda que tenha sido importante, o aumento das matrículas nas IES públicas "não foi suficiente para alterar a predominância da rede privada, que deteve $68,9 \%$ do total geral de matrículas registradas em 2001 e atingiu $74,2 \%$ em $2010 "$.

Com a expansão do acesso, diversificou-se o público estudantil, trazendo às universidades, estudantes que seriam as primeiras gerações familiares a acessar este nível de escolaridade. Para muitos dos recém-chegados, a adaptação ao ambiente universitário tornou-se um problema de múltiplas dimensões, permeado por questões que vão do campo estrutural ao campo subjetivo. A diversificação do público da educação superior a partir dos anos 2000, instiga a necessidade de averiguar configurações e problemas do processo de integração dos estudantes à educação superior.

O processo de integração, define-se aqui, como uma demanda dos estudantes da educação superior nos seus primeiros contatos com as instituições, devendo voltar-se à produção de suportes que favoreçam a elucidação de dúvidas e a compreensão das rotinas, da estrutura, das relações e da lógica que rege a organização e o funcionamento deste nível de ensino no Brasil, considerando suas radicais diferenças com relação à educação básica.

Enquanto processo que requer, necessariamente, colocar em diálogo diferentes sujeitos, quais sejam, aqueles que conhecem a experiência institucional e os recém-chegados, a integração pode envolver ações planejadas e contínuas, conduzidas por setores como departamentos, coordenações, centros acadêmicos, entre outros. Como também é um processo que abarca ações de caráter instituinte ou até mesmo não institucionais, como as ações organizadas e promovidas entre os pares estudantis e as ações de apoio providenciadas pelas famílias. Nesse estudo, o foco encontra-se nas ações institucionais.

Os dados referentes à relação acesso-permanência também reforçam a importância de estudar a dinâmica que permeia o processo de inserção dos jovens no ambiente universitário, uma vez que apontam o crescimento da evasão no ensino de graduação nos primeiros anos de estudo (COULON apud PERETTA; OLIVEIRA; LIMA, 2019).

A Lei de Diretrizes e Bases da Educação Nacional, Lei no 9.394/1996 estabelece uma relação verticalizada entre os níveis de educação, de modo que a conclusão da educação básica, finalizada no ensino médio, é condição de acesso à educação superior, no nível de graduação (LDBEN, Art. 44, II). Sabe-se que a vivência desta passagem é mais complexa que a relação linear e causal sugerida pela Lei, daí a importância de historicizar o processo de transição entre níveis enquanto objeto de conhecimento científico, interrogá-lo em suas múltiplas manifestações para melhor compreendê-lo e atuar política e pedagogicamente sobre ele.

Referindo-se ao processo de integração de jovens de camadas populares em universidades públicas, Tarábola (2019, p. 4) destaca que, ao ingressar na universidade, estes jovens "precisaram agir para dominar as regras, se apropriar dos códigos secretos das linguagens, procedimentos, instâncias e siglas e, inclusive, descobrir as temporalidades ocultas que regem a vida universitária de um estudante tido como competente".

O pertencimento socioeconômico rebate em dificuldades financeiras para aquisição de materiais, pagamento de transporte, alimentação etc., além de ter implicações na disponibilidade 
de tempo para dedicação ao curso e no próprio processo de escolha profissional Zago (2006). Este também é debate necessário na exploração do tema, visto que a pesquisa aborda um curso de licenciatura cuja maioria dos estudantes provém das classes populares.

Outro aspecto a considerar diz respeito ao fato de que a escola de ensino médio brasileira está ainda organizada sobre uma ideia de discente tutelado, que dificulta o desenvolvimento da autonomia e capacidade de decisão sobre os próprios rumos de sua formação, aspectos que lhes serão mais exigidos no nível da educação superior.

As pesquisas que se ocupam das questões relacionadas aos processos formativos juvenis no âmbito dos sistemas de ensino, mantêm-se desde a década de 1990 como tema de grande expressão no conjunto da produção da área da educação (SPOSITO; TARÁBOLA, 2017). Delimitando o foco nos recortes "juventude e ensino médio" e "juventude e educação superior", observa-se que ao longo dos últimos vinte anos, produziu-se um número significativo de trabalhos acadêmicos, porém, as questões relacionadas ao processo de transição dos jovens entre estes dois níveis de ensino ainda precisam ser exploradas.

Mediante a problemática aqui enunciada, o estudo coloca em debate as seguintes questões: Quais os desafios atuais vivenciados pelos jovens no processo de transição do ensino médio à educação superior? Como se configura o processo de integração de novos estudantes no curso de Pedagogia da Faculdade de Educação da Universidade Federal do Amazonas?

A pesquisa tem abordagem qualitativa e retoma fundamentos teórico-metodológicos da área da educação para a compreensão dos aspectos político-pedagógicos envolvidos no processo de transição do ensino médio para a educação superior, fazendo interface com conceitos da metodologia que favorecem a compreensão das relações dos jovens com os processos formativos realizados dentro dos sistemas de ensino formais.

Foram analisados informativos e folders institucionais, notícias e outros conteúdos dispostos no site institucional e o Projeto Pedagógico de Curso - PPC - do curso de Pedagogia da FACED, com o intuito exploratório de verificar quais as ações institucionais voltadas para o processo de integração dos jovens calouros do curso de Pedagogia nos anos de 2019 e 2020 e como se configuram estas ações. Os dados foram sistematizados e analisados qualitativamente tendo como parâmetros os objetivos da pesquisa. Por meio da técnica de análise de conteúdo (FRANCO, 2018), buscou-se identificar tendências e recorrências no conteúdo dos documentos analisados e a construção de categorias explicativas do problema de pesquisa.

$\mathrm{O}$ artigo encontra-se organizado em três seções articuladas entre si, além desta introdução e das considerações finais. Na primeira seção, são apresentados desafios que permeiam o processo de transição dos estudantes do ensino médio à educação superior, quais sejam: a ruptura da cultura do ensino médio para a do ensino superior, as desigualdades sociais, a hierarquização dos cursos superiores entre aqueles de mais ou menos prestígio social. Na segunda seção, são abordados alguns dilemas da vida universitária, que tem ligação direta com os desafios tratados no item anterior. Entre esses dilemas destacam-se: as questões ligadas a logística, custos com o curso e vulnerabilidade financeira, limitação aos programas institucionais de bolsas de estudo e a fragilidade do processo formativo na educação básica. Por fim, na última seção, analisa-se a experiência da Faculdade de Educação da UFAM na promoção de ações de acolhimento de discentes recém-chegados na instituição.

\section{Desafios que permeiam a transição do ensino médio à educação superior}

Historicamente, os cursos de graduação foram se constituindo, no imaginário social, como a grande aposta de continuidade de estudos pós ensino médio, sendo essa ideia impulsionada, a partir dos anos 2000, pela expansão da oferta de vagas neste nível de ensino e pela articulação com fatores de cunho econômico. 
O dinamismo econômico, a geração de postos de trabalho formais [...], os efeitos da universalização do ensino fundamental (e também de suas desigualdades em termos de qualidade) e da expansão das vagas no ensino médio, todos esses fatores alteram as pressões pelo acesso ao ensino superior. (JARDIM; ALMEIDA, 2016, p. 72).

Esses cursos, conforme determina a LDBEN/1996, são acessíveis a todos aqueles que concluíram o ensino médio e que sejam aprovados em processos seletivos (Art. 44, II). Na realidade atual, os jovens tornaram-se sujeitos centrais deste projeto social, pela expressividade da população até 29 anos de idade nas matrículas da educação superior (BRASIL/INEP, 2019).

Nos limites desse texto, não será possível o desdobramento da discussão sobre as desigualdades que permeiam o processo de expansão de matrículas e a presença juvenil na educação superior quando consideradas variáveis como renda, cor e gênero, mas isto é algo que na leitura deste estudo, precisa ser considerado. Picanço (2015) afirma que os anos 2000 sinalizaram um maior acesso ao ensino superior dos grupos em desvantagem, como os negros e mais pobres, mas que esse acesso não implica uma queda brusca da desigualdade em relação aos grupos em vantagem, pelo contrário, a tendência é de uma queda muito lenta das desigualdades.

A simples previsão de uma obrigatoriedade de conclusão do ensino médio para o acesso ao curso de graduação, não confere a articulação necessária para um projeto bem sucedido de transição entre estes níveis de ensino. É nesse ponto que a transição deixa de ser um projeto coletivo e torna-se um projeto individual e, para muitos jovens, um momento de muitas dificuldades.

Nesse contexto, o acesso à educação superior representa um momento de ruptura com muitos dos elementos da cultura escolar com os quais os estudantes estavam familiarizados. Nos cursos de graduação, o estudante se depara com uma cobrança maior quanto à autonomia e responsabilidade com a gestão da própria formação e depara-se com novos códigos de relações com colegas e professores (FARIA; ALMEIDA, 2020).

$\mathrm{Na}$ ausência de um projeto formativo articulado e coletivo, as dificuldades podem se tornar grandes entraves e verdadeiros dilemas a serem contornados pelos jovens em processo de transição. No cálculo das possibilidades entre dificuldades e condições de superá-las, a desistência, mesmo que provisória, tem tomado o lugar da persistência para um número significativo de jovens brasileiros.

A permanência no ensino superior tem sido objeto de muitas discussões nos últimos anos (FARIA; ALMEIDA, 2020). Os estudos defendem que trabalhar visando a permanência dos discentes não se restringe a oferecer ingresso com ampla oferta de vagas ou customizar o processo seletivo, mas, sobretudo, elaborar programas e ações voltados à fixação do estudante na instituição (LIMA, 2018).

No atual cenário brasileiro, os processos seletivos, que são uma exigência para o acesso aos cursos de graduação, são oferecidos em diferentes modalidades, havendo processos destinados ao público geral que comprove conclusão do ensino médio ou equivalente e processos contínuos, com provas anuais aplicadas conforme as séries do ensino médio cursadas pelos candidatos.

Na primeira modalidade, destacam-se o Exame Nacional do Ensino Médio (ENEM) ${ }^{2}$, cujo resultado na prova é considerado para acesso em muitas das Universidades e Institutos Federais, via Sistema de Seleção Unificada - SISU -, e em muitas instituições privadas. As instituições públicas e privadas que não aderiram ao ENEM, permanecem com seus vestibulares próprios. Na UFAM, instituição lócus da pesquisa, destinam-se 50\% das vagas para o SISU, sendo o restante distribuído em outros processos seletivos próprios.

$\mathrm{Na}$ modalidade de processos contínuos, a UFAM disponibiliza 50\% do total de vagas para o Processo Seletivo Contínuo - PSC -, com provas anuais aplicadas conforme a série do ensino médio. Nesse processo, a escolha do curso ocorre na fase final de provas.

2 O ENEM foi criado em 1998, com o objetivo inicial de ser utilizado como instrumento de avaliação do desempenho dos estudantes do ensino médio. Apenas em 2009 o exame passou a ser utilizado como ferramenta de acesso ao ensino superior no Brasil (SILVEIRA; BARBOSA; SILVA, 2015). 
É preciso considerar que o público que se submete a esses processos, carrega consigo a histórica desigualdade que permeia os sistemas de ensino brasileiro, de modo que muitos concorrem em condições desiguais. Conforme destaca Cury (2002, p. 179), o fator que determina a situação do Brasil é "[...] a extrema desigualdade socioeconômica que atende pelo nome de pobreza ou de miséria e significa a exclusão histórica e atual de um número significativo de estudantes provindos de famílias de baixa renda".

Sobre o acesso dos jovens de classes populares à educação superior, Zago (2006) destaca que a desigualdade tem desdobramentos desde o processo de escolha do curso.

O ensino superior representa para esses estudantes um investimento para ampliar suas chances no mercado de trabalho cada vez mais competitivo, mas, ao avaliar suas condições objetivas, a escolha do curso geralmente recai naqueles menos concorridos e que, segundo estimam, proporcionam maiores chances de aprovação. (ZAGO, 2006, p. 231).

Dentro de um sistema de transição entre níveis escolares baseado em exames, a nota torna-se parâmetro de sucesso ou o fracasso escolar do indivíduo, escamoteando que o verdadeiro fracasso estaria no sistema forjado sobre a desigualdade. Este é o sistema que reduz pessoas a notas, e é comumente utilizado nas universidades do Brasil, promovendo a hierarquia das profissões, existente no mundo inteiro.

Segundo Bourdieu e Saint-Martin (1998), um dos grandes propulsores desse sistema classificatório está na própria escola, mais especificamente dentro da sala de aula, no qual o professor é capaz de selecionar ou segregar seus alunos desde o início da vida escolar. Desta maneira, segue-se este padrão de classificação na sociedade até a vida universitária.

Vê-se que o sistema de classificação escolar (obtido aqui através dos adjetivos empregados no elogio fúnebre) continuou a funcionar ao longo da carreira universitária como instrumento dissimulado de classificação social: é notável que no conjunto dos "antigos alunos" formalmente iguais e realmente igualados - do ponto de vista dos critérios escolares - pelo efeito de superseleção, o sistema escolar tenha continuado a estabelecer, em função dos mesmos critérios por meio dos quais foram selecionados, hierarquias diretamente manifestadas nas carreiras universitárias. (BOURDIEU; SAINT-MARTIN, 1998, p. 205).

A hierarquização de cursos tem ainda relação com as áreas do conhecimento a que se vinculam e seus lugares nos rankigns de investimentos do fundo público e nos currículos escolares. No campo da distribuição de recursos, as humanidades padecem com os parcos montantes financeiros que se lhes destinam há muitos anos. No que concerne aos currículos escolares, a Lei no 13.415/2017 relega componentes curriculares como Educação Física, Artes, Sociologia e Filosofia a um plano secundário na matriz do ensino médio (FERRETTI, 2018).

Desta maneira, configura-se um conjunto de elementos que interferem diretamente nas escolhas estudantis, favorecendo o receio de muitos em fazer escolhas por áreas que enxergam como menos prestigiadas e valorizadas socialmente.

Além dos fatores citados, há outros que envolvem a transição do ensino médio ao superior. As longas jornadas de estudo para conseguir uma vaga na universidade, a administração das inseguranças comuns na fase da adolescência, a conciliação de estudos com trabalho que pode afetar o desempenho escolar.

Para muitos, a última etapa da educação básica é vista somente como uma condição anterior à entrada na faculdade, porém o foco do ensino médio não é treinar alunos para prestarem vestibulares.

Legalmente falando, o ensino médio não é, como etapa formativa, nem porta para o ensino superior e nem chave para o mercado de trabalho. Ele tem uma finalidade em si, embora seja requisito tanto do ensino superior quanto da educação profissional de nível técnico. (CURY, 2002, p. 182). 
Isso posto, conclui-se que a finalidade do ensino médio está para além dos exames para acesso ao ensino superior, ao que esse pode ser apenas uma parcela de um projeto de vida do estudante. $\mathrm{Na}$ próxima seção buscaremos esmiuçar dilemas e dificuldades do cotidiano dos jovens nos primeiros contatos com a educação superior, com foco na realidade de instituições públicas.

\section{Dilemas da vida universitária: primeiras conexões com a universidade pública}

$\mathrm{O}$ acesso ao ensino superior caracteriza-se como um processo complexo, principalmente para os estudantes das camadas populares. Nesse caso, a possibilidade de permanência é frágil, posto que os dilemas que se impõem a esse acadêmico são inúmeros.

Um dos primeiros dilemas citados por estudantes com relação à permanência na universidade, diz respeito à locomoção e/ou mobilidade, problema que atinge especialmente os estudantes dos grandes centros urbanos. Diferente da educação básica, cujas unidades escolares se distribuem por todas as regiões das cidades, a oferta da educação superior concentra-se em um número bem menor de instituições, nucleadas em regiões que nem sempre são de fácil acesso aos estudantes.

Nas grandes cidades e principalmente naquelas com maiores problemas de mobilidade urbana, pode-se perder muito tempo dentro de transportes coletivos de baixa qualidade, com longos e engarrafados percursos que tornam a assiduidade e a frequência às aulas exaustivas e penosas, além de consumir diariamente parcela significativa do tempo do estudante que, não fosse isto, poderiam ser aplicados aos estudos ou realização de trabalhos acadêmicos.

Em que pese o cenário das políticas públicas voltadas para o ensino superior, a evasão universitária tem se tornando uma das questões mais preocupantes da educação devido os altos índices de abandono tanto em instituições públicas como, principalmente, em instituições privadas.

Em um estudo realizado pelo Instituto Nacional de Estudos e Pesquisas Educacionais (INEP) 2006, concluiu-se que o fenômeno da evasão ocorre em maior número nas IES privadas, apresentando índices de $53 \%$ contra $33 \%$ nas públicas. Isso, em virtude das instituições privadas possuírem $60 \%$ das vagas oferecidas aos estudantes que participam de processo seletivo para entrarem no ensino superior. (MELO, 2017, p. 50).

Situações como organização do campus, integração ao ensino superior, relacionamento com o colegiado e os demais docentes, desempenho acadêmico, dentre outros, podem demonstrar se a universidade está sendo facilitadora ou inibidora do fenômeno da evasão (MATTA, 2011).

A situação da permanência na educação superior está relacionada também com a possibilidade de o estudante arcar com os custos financeiros que ela requer. A rotina universitária exige gastos diários com transporte, alimentação, aquisição de material etc. A realidade daqueles que necessitam permanecer em período integral nas instituições de ensino, seja por obrigatoriedade curricular ou por opção, pode ser ainda mais delicada.

Para os estudantes das classes populares conciliação dos estudos com o exercício de atividades remuneradas é uma condição também para a permanência. Neste aspecto, a oferta de programas que proporcionem apoio financeiro ao estudante, tais como as bolsas de iniciação científica, iniciação à docência, monitoria, dentre outros programas de apoio, representam um diferencial para a permanência discente.

Para além do auxílio financeiro, o acesso aos programas institucionais que viabilizam bolsas, tem relevante contribuição na formação dos acadêmicos (SEVERINO, 2016). Porém, é preciso mencionar que esse acesso é seletivo e limitado, tanto porque não há cotas de bolsas suficientes para todos, quanto é preciso reconhecer que para muitos estudantes, os valores de bolsas são insuficientes para suprimento de suas necessidades materiais, seja pela extrema vulnerabilidade econômica, seja pela posição que assumem no provimento do núcleo familiar. 
Além de contribuir para a permanência no curso, a busca por emprego durante a formação acadêmica ocorre, também em virtude de conquistas de vantagens na hora da busca por empregos posteriores, visando a carga de experiências que poderão possuir durante o período da faculdade (ABDAL; NAVARRA, 2014).

O árduo caminho de quem opta por trabalhos mais convencionais ou estágios remunerados fora da universidade se torna mais difícil devido ao aluno ter que escolher entre se dedicar mais a sua única fonte de renda ou aos seus estudos, prejudicando o desenvolvimento do acadêmico.

Nos primeiros anos da graduação, também repercutem dificuldades que remontam às fragilidades do processo formativo na educação básica. Diversos alunos chegam à universidade sem a prática de leitura e escrita e outros conhecimentos gerais de base que lhes serão exigidos para o acompanhamento das atividades acadêmicas.

Para amenizar esta fragilidade, alguns cursos mantêm em sua matriz curricular a disciplina de Metodologia do Trabalho Científico, o que por si só não é suficiente para as situações que os alunos irão vivenciar durante a graduação. Em contrapartida, o foco da disciplina não é ensinar os alunos a compreenderem o que leem, pois este é o papel da educação básica, no entanto "a Metodologia Científica, mais do que uma disciplina, significa introduzir o discente no mundo dos procedimentos sistemáticos e racionais, base da formação tanto do estudioso quanto do profissional [...]" (MARCONI; LAKATOS, 2003, p. 17).

Outro dilema vivenciado na universidade, diz respeito à burocracia institucional que os alunos oriundos do ensino médio não estão habituados. Nesse momento, os estudantes se dão conta de que não serão mais seus pais que resolverão seus problemas pessoais e de cunho burocrático, mas sim eles mesmos terão o dever de encontrar as resoluções para os seus dilemas. Neste contexto, novas reações comportamentais são esperadas dos jovens para lidar com contratempos desencadeados pela nova rotina, comumente denominada de período de adaptação ou integração ao ensino superior (ALBANAES et al., 2014).

Destarte, essas situações estimulam e afloram, dinamicamente, o amadurecimento intelectual, profissional e pessoal do aluno.

Espera-se um maior envolvimento dele nas tarefas, maior autonomia e responsabilidade com a aprendizagem, ou seja, um compromisso próprio de um jovem a caminho da idade adulta, pautada por maior responsabilidade no que diz respeito à participação nas aulas e realização dos trabalhos acadêmicos. (FARIA; ALMEIDA, 2020, p. 03).

No entanto, por situações antes expostas, a falta de autonomia de alguns acadêmicos pode ser impedimento na busca de informação, na manifestação da necessária responsabilidade pode acarretar problemas dos mais simples aos mais graves, como o impedimento da permanência do estudante na universidade.

Esses são apenas alguns dos desafios encontrados pelos alunos da graduação durante a sua permanência na universidade, cuja função, nesse contexto, é em primeiro lugar de promover processos de integração dos novos estudantes de maneira efetiva, para que os dilemas da vida acadêmica não sejam individuais, mas coletivos, e, em segundo lugar tornar esse processo de transição menos penoso e, em um plano ideal, garantir a permanência do acadêmico na universidade. A partir das questões discutidas, na próxima seção buscaremos esclarecer quais ações de acolhimento a Universidade Federal do Amazonas tem buscado para integrar seus discentes. 


\section{O processo de integração de calouros na Faculdade de Educação da Universidade Federal do Amazonas}

A Faculdade de Educação da Universidade Federal do Amazonas - FACED/UFAM - é uma unidade de ensino que completou, no ano de 2020, seu cinquentenário, tendo, ao longo de sua trajetória, relevante papel na formação de pedagogos e outros quadros profissionais para atuarem na educação básica na região norte. Para a reflexão sobre o processo de integração de seus jovens estudantes na atualidade, torna-se importante mencionar esta história na perspectiva defendida por Lima (2020, p. 107),

Qualquer instituição que complete cinquenta anos de funcionamento acaba por realizar os fins para os quais foi planejada. Isso porque uma instituição de tanto tempo, mesmo que em seu caminho tenha havido percalços e reformulações, teve o seu programa como realizador de um processo de socialização dos indivíduos que perpassou várias gerações.

Atualmente, a FACED oferece, no nível de graduação, os cursos de Pedagogia e Formação de Professores Indígenas. Nos limites desse estudo, serão analisadas as ações de acolhimento e integração a calouros do curso de Pedagogia.

O curso de Pedagogia da Faculdade de Educação da UFAM, configura-se atualmente como uma licenciatura plena, que habilita o licenciado para atuação nas seguintes dimensões: docência na educação infantil e anos iniciais do ensino fundamental; gestão da educação e produção e difusão do conhecimento científico e tecnológico do campo educacional (UFAM, 2019).

Para pensar sobre a realidade do estudante recém-chegado nesse curso, é importante pontuar que as licenciaturas têm exercido pouca atratividade dos estudantes do ensino médio, sendo este um dado que as instituições não podem ignorar nas relações estabelecidas com os jovens estudantes desde sua entrada no curso.

No estudo de Tartuce, Nunes e Almeida (2010, p. 446), os estudantes apontam as seguintes justificativas para a falta de atratividade da carreira docente: "ausência de identificação pessoal com a docência, às condições sociais e financeiras de exercício da profissão, à própria experiência escolar dos alunos e à influência familiar".

Segundo Aranha e Souza (2013), a baixa atratividade da carreira docente, transforma esses cursos naqueles de menor concorrência nos processos seletivos, fator muitas vezes primordial na avaliação de possibilidades feita pelo jovem em processo de escolha.

Diante do cenário geral de baixa atratividade observada para as licenciaturas, cabe dizer que a Pedagogia tem sido menos afetada por este fenômeno, visto que ainda é um curso que desperta o interesse de muitos candidatos dos processos seletivos, sendo a licenciatura com o maior número de matrículas no Brasil e o segundo curso no total geral de matrículas no ano de 2019 (BRASIL/INEP, 2019).

No caso do curso de Pedagogia da UFAM, os dados apontados por Freire (2015) referentes ao período de 2012-2014 demonstram que, apesar de muitos estudantes alegarem que a baixa concorrência foi um dos motivos para a escolha do curso, a Pedagogia varia no período citado entre o terceiro e quarto lugares na relação de candidatos por vaga na área de Humanas, sendo sempre a licenciatura de maior índice na relação candidato/vaga.

Observando-se os dados relacionados ao preenchimento de vagas ofertadas nos processos seletivos dos últimos anos, constata-se que ainda é um curso de licenciatura muito procurado, tendo em vista que foram preenchidas respectivamente $100 \%$ e 99,4\% do total de 168 vagas ofertadas nos anos de 2019 e 2020. Ainda que se registre que o número de chamadas de matrícula em listas de espera para o preenchimento destas vagas venha crescendo ano após ano. 
Todavia, o preenchimento de vagas não deve ser lido, isoladamente, como um dado que atesta o interesse dos estudantes ingressantes pelo curso. Em estudo realizado junto aos estudantes do curso de Pedagogia da UFAM, Freire (2015, p. 76) aponta dados intrigantes.

Foi observado que dos alunos participantes no Grupo Focal, 63\% declararam que já pensavam em ser professor quando escolheram o curso de pedagogia. [...] Em contraposição, 25\% afirmaram que nunca haviam pensado em ser professor e $6 \%$ que pensavam no curso de pedagogia, mas na perspectiva de ser especialista e não professor. Além disso, $6 \%$ dos alunos manifestaram que não desejam ser professor mesmo depois de formado.

Afirma-se com isso que as circunstâncias que permeiam a escolha dos estudantes, bem como o nível de informações que possuem sobre o curso são aspectos importantes a serem considerados pelas instituições na proposição de ações de acolhimento e integração.

A finalidade da Universidade Federal do Amazonas, proclamada em seu Estatuto, é "cultivar o saber em todos os campos do conhecimento puro e aplicado", missão que não se cumpre sem a conjugação de esforços dos diferentes sujeitos da comunidade acadêmica, apoiados pelas estruturas necessárias ao trabalho acadêmico na universidade.

A universidade configura-se como um projeto de grande envergadura social, cujo trabalho pedagógico deve pautar-se no princípio da qualidade socialmente referenciada, construindo propostas que enfrentem os processos de exclusão ao invés de reproduzi-los. Zelar pela permanência dos discentes, valorizando-os como sujeitos concretos que expressam as contradições de um tempo espaço-socialmente referenciados, é uma maneira de caminhar na direção de sua finalidade.

As atividades de acolhimento de calouros podem assumir diferentes configurações nas instituições de ensino superior, sendo comum apresentarem-se sob a forma de eventos de recepção previstos em seus calendários acadêmicos, distribuição de materiais informativos sobre o funcionamento da instituição, ações de apresentação de setores via visitação in loco, até ações curriculares articuladas a disciplinas, projetos e/ou outros componentes curriculares.

Essas práticas voltadas à integração do estudante à universidade devem capacitá-lo a lidar, de maneira produtiva e significativa com as características desse contexto. As atividades de acolhimento ao calouro constituem uma das possíveis ações a serem realizadas para produção desses objetivos e auxiliam, portanto, na dimensão da adaptação e permanência do estudante nessas instituições. (ALBANAES et al., 2014, p. 146).

Na UFAM, registrou-se nos anos de 2019 e 2020 a realização de evento de acolhida aos calouros dos cursos oferecidos nas unidades do Campus Manaus, promovido no Centro de Convivência do Setor Norte. A programação agrega atividades de entretenimento, convivência e informação e é realizada na primeira semana de aula.

A programação do ano de 2020 contemplou atividades como: palestras e conversas sobre saúde mental, Coronavírus, meio ambiente e sustentabilidade, prevenção ao abandono de animais, dentre outros temas. Além disso, foram realizados shows musicais e de humor, tour pelos espaços da instituição dentre outros (UFAM, 2020).

Uma peculiaridade do ano de 2020, foi a suspensão das atividades acadêmicas presenciais nas instituições de ensino em decorrência da pandemia de covid-19 declarada em 11 de março de 2020 pela Organização Mundial da Saúde. Na UFAM, as atividades presenciais foram suspensas pela da Portaria no 626, de 13 de março de 2020, a partir do dia 16/03/2020, sendo que o período letivo havia iniciado no dia 09/03/2020.

Interessante notar que o tema do Coronavírus já estava presente na programação de acolhida, ainda que àquela altura fosse difícil calcular efeitos de uma pandemia sobre a trajetória acadêmica daquele grupo de jovens calouros da UFAM e de crianças, jovens e adultos do mundo inteiro. 
Esse parêntese é importante porque chama a atenção para a particularidade do tema da integração quando se trata do grupo de ingressantes de 2020. Aqui serão abordadas as poucas ações que lhes alcançaram na vigência das atividades presenciais, mas na sequência dessa ou em outras pesquisas, será importante olhar para o que aconteceu com este grupo em termos de integração institucional no período de atividades remotas.

Com relação aos eventos gerais de acolhimento a calouros realizados pela UFAM nos anos de 2019 e 2020, é importante mencionar que não estão previstos no Calendário Acadêmico, incorrendo-se assim no risco de conflito de horário ou sobreposição de conteúdos e ações com outras atividades propostas pelas Unidades Acadêmicas e/ou pelos Centros Acadêmicos.

No âmbito da Faculdade de Educação, registram-se, para o período de 2019 e 2020 dois tipos de atividades de integração que podem ser consideradas como produtoras de suporte aos estudantes recém-ingressos no curso. O primeiro tipo de ação se configura como evento de acolhimento de estudantes e abertura do semestre letivo e a segunda ação tem natureza curricular e denomina-se como Primeiro Seminário de Integração.

Como mencionado anteriormente, esse estudo faz referência às atividades planejadas e promovidas no nível institucional, e no caso do curso de Pedagogia, organizadas pelo Colegiado de curso, instância deliberativa composta por coordenador(a) pedagógico(a), representante docente dos departamentos acadêmicos da FACED, representante docente de cursos de outras unidades que oferecem disciplinas obrigatórias no curso de Pedagogia, representante dos técnicos administrativos e representante discente. As atividades de integração estão previstas no Calendário Letivo da Faculdade de Educação, aprovados em instâncias colegiadas.

Os eventos de acolhimento envolvem atividades desenvolvidas ao longo do primeiro mês do calendário acadêmico, concentrando-se principalmente nas duas primeiras semanas. A programação desenvolvida em 2019 e 2020 segue um padrão que se desdobra nos seguintes itens: falas de representantes institucionais da Direção, Departamentos, Coordenações e Centro Acadêmico; aula inaugural sobre temática da área da educação; articulação com atividades coordenadas pelo Centro Acadêmico; apresentação de núcleos de pesquisa; exposição de setores institucionais responsáveis por Programas de Auxílio Acadêmicos.

A análise documental permite concluir que nos eventos de acolhimento promovidos pela FACED, há um esforço de promover a integração dos novos discentes em duas dimensões: a primeira representada pela disponibilização de informações sobre a organização e o funcionamento da instituição; e a segunda pela sensibilização dos recém-chegados para temas relevantes na área da educação, viabilizada pelas aulas inaugurais temáticas, proferidas por docentes da instituição e pelas apresentações dos núcleos de pesquisa.

Passando a abordar o Primeiro Seminário Integrador, que aqui está sendo considerado como uma face curricular do processo de integração de novos estudantes no curso de Pedagogia da FACED/UFAM, trata-se de uma atividade prevista no Projeto Pedagógico do Curso de Pedagogia, implantado no ano de 2019. É oferecido em caráter obrigatório para estudantes do primeiro período de Pedagogia, com carga horária de 10h, sob a coordenação do Colegiado (UFAM, 2019)3.

O Seminário intitula-se A dinâmica de funcionamento e sistemática curricular e metodológica do curso de Pedagogia, desdobrando-se nos seguintes temas: "Apresentação e especificação do PPC do curso e dos planos e projetos de desenvolvimento pedagógico do curso" (UFAM, 2019, p. 37).

Em ambos os anos, observa-se que as atividades referentes ao Seminário estavam previstas no Calendário Acadêmico da FACED, e algumas chegam a compor a programação de recepção promovida nas primeiras semanas de aula. Observa-se que a preocupação central no Seminário

\footnotetext{
3 Ao todo o currículo do Curso de Licenciatura em Pedagogia da UFAM, versão 2019, contempla 6 Seminários Integradores, articulados a diferentes momentos formativos do Curso. Somente o primeiro está sendo abordado neste estudo, por estar voltado à temática da integração dos estudantes.
} 
é situar os novos estudantes, no Projeto Pedagógico de Curso, bem como apresentar os planos e projetos que o viabilizam. Nessa perspectiva, há uma complementaridade entre o Seminário e a Programação Geral de acolhimento prevista no Calendário Institucional.

Nesta proposta de integração de novos estudantes que vem sendo construída na FACED/ UFAM, destacam-se como pontos fortes a busca pela continuidade das ações, a multiplicidade de atores envolvidos na organização do evento, inclusive a articulação com a entidade estudantil, a inserção no calendário acadêmico e, no caso do Seminário Integrador, no PPC e a aprovação do calendário em instâncias colegiadas, que sugere um processo de discussão da programação proposta.

Como ponto de atenção, destaca-se que o PPC, não traz considerações sobre o perfil dos ingressantes na educação superior na atualidade e, sobretudo das especificidades do perfil do graduando da Pedagogia. Algo que, avalia-se, seria importante para fortalecer a concepção e as propostas de integração de novos estudantes que vêm sendo realizadas no curso. Naquilo que foi possível observar a partir da análise documental, observa-se também que a proposta de integração de novos estudantes na FACED, não tem explorado a contento, processos de escuta dos recém-chegados, a fim de sondar aspectos de seu perfil socioeconômico e escolar, circunstâncias que permeiam a escolha e/ou o nível de informações que possuem sobre o curso etc.

Por ora, buscou-se evidenciar a configuração dessa experiência institucional em caráter ainda exploratório, de modo que ajude a pensar o processo de integração de estudantes na educação superior. O aprofundamento da análise dos desdobramentos dessas ações, além da escuta dos membros da comunidade acadêmica por ela alcançados, é um processo que se anuncia como relevante para outras etapas do estudo.

\section{Considerações Finais}

Essa pesquisa situou-se no âmbito dos estudos em educação, pois aborda a configuração dos atuais processos de transição entre a educação básica e a educação superior e objetivou analisar as ações institucionais voltadas à integração de novos estudantes ao ambiente universitário.

Discutiu os desafios atuais vivenciados pelos jovens no processo de transição do ensino médio à educação superior, bem como as estratégias desenvolvidas pelo curso de Pedagogia da Faculdade de Educação da Universidade Federal do Amazonas no processo de integração de novos estudantes.

No que se refere a esse processo, os documentos analisados apontaram que a Faculdade de Educação dessa instituição propõe oficialmente e realiza ações pontuais de integração dos estudantes ingressantes em seu quadro discente.

Constatou-se que a Faculdade de Educação possui calendário e atividades de acolhimento aos calouros, o que sugere interesse institucional de enfrentamento aos processos de exclusão social por proporcionar ao público-alvo vivências acadêmicas que podem corroborar no domínio do ambiente universitário.

Quanto aos processos de integração dos acadêmicos recém-chegados nos anos 2019/2020, realizou-se em duas ações distintas: evento de acolhimento de estudantes e abertura do semestre letivo e a segunda ação, de natureza curricular, denominada Primeiro Seminário de Integração.

Concluiu-se que nessas ações da FACED há um esforço de integração dos acadêmicos novos no que se refere à disponibilização de informações sobre a organização e o funcionamento da instituição, e a sensibilização dos recém-chegados para temas na área da educação, viabilizada pelas aulas inaugurais temáticas, na primeira ação.

Da mesma forma, o Primeiro Seminário de Integração, cujo objetivo primeiro é situar os novos estudantes no Projeto Pedagógico de Curso e apresentar os planos e projetos que o viabilizam, configura-se como peça importante no processo de integração do novo acadêmico. 
Outro aspecto a ser destacado é que esse esforço de integração é articulado sobre princípios de deliberação coletiva e participação de diferentes atores, pois, como observou-se nos documentos analisados, são ações organizadas pelo Colegiado de Curso, instância deliberativa composta por coordenador(a) pedagógico(a), representante docente dos departamentos acadêmicos da FACED, representante docente de cursos de outras unidades que oferecem disciplinas obrigatórias no curso de Pedagogia, representante dos técnicos administrativos e representante discente.

Essa pesquisa não possibilitou analisar os impactos das ações de integração que foram desenvolvidas nos anos de 2019 e 2020 no que diz respeito a colaboração para a permanência dos estudantes na instituição, mas pode-se afirmar que ações de integração são necessárias dada a complexidade do ambiente acadêmico e a mudança da realidade do ensino médio para a realidade do ensino superior. E, como dito nesse texto, os acadêmicos que são o público do curso de pedagogia são jovens que enfrentam limitações, especialmente socioeconômicas, os quais chegam à universidade com seus desafios e dilemas e, portanto, necessitam de aportes institucionais para não se perderem no início do caminho.

Nesse sentido, sem a pretensão de afirmar que as ações de integração realizadas na FACED sejam suficientes e adequadas, pode-se concluir que há em construção nessas ações, uma proposta de enfrentamento dos processos de exclusão social. Um projeto que busca contribuir com a permanência dos discentes no ambiente acadêmico.

Para estudos futuros, pode-se propor pesquisa que envolva os acadêmicos como participantes do estudo para a verificação dos impactos dessas ações no percurso acadêmico, na eficácia dessas ações de integração e em como os acadêmicos são afetados por elas para a permanência, ou não, no curso, dando, dessa forma, ferramentas de avaliação e aperfeiçoamento das ações de integração de novos acadêmicos.

\section{Referências}

ABDAL, Alexandre; NAVARRA, Julia. "Uni por Uni, eu escolhi a que era do lado da minha casa": Deslocamentos cotidianos e o acesso, a permanência e a fruição da universidade por bolsistas do ProUni no Ensino Superior privado. Novos estudos CEBRAP, São Paulo, n. 99, p. 65-87, jul. 2014. Disponível em: https://www.scielo.br/pdf/nec/n99/0101-3300nec-99-00065.pdf. Acesso em: 24 jan. 2021.

ALBANAES, Patrícia et al. Do trote à mentoria: levantamento das possibilidades de acolhimento ao estudante universitário. Revista Brasileira de Orientação Profissional, São Paulo, v. 15, n. 2, p. 143-152, jul./dez. 2014. Disponível em: https://www.redalyc.org/pdf/2030/203040852005.pdf. Acesso em: 24 jan. 2021.

ARANHA, Antônia Vitória Soares; SOUZA, João Valdir Alves de. As licenciaturas na atualidade: nova crise? Educar em Revista, Curitiba, n. 50, p. 69-86, out./dez. 2013. Disponível em: http://dx.doi.org/10.1590/S0104-40602013000400006. Acesso em: 21 jan. 2021.

BARROS, Aparecida da Silva Xavier. Expansão da educação superior no brasil: limites e possibilidades. Educação \& Sociedade, Campinas, v. 36, n. 131, p. 361-390, abr./jun. 2015. Disponível em: http://dx.doi.org/10.1590/ES01017330201596208. Acesso em: 23 mar. 2020.

BOURDIEU, Pierre; SAINT-MARTIN, Monique. As categorias do juízo professoral. In: NOGUEIRA, Maria Alice; CATANI, Afrânio Mendes (org.). Escritos de Educação. Petrópolis: Vozes, 1998. p. 187-216.

BRASIL. Lei no 9394, de 20 de dezembro de 1996. Estabelece as diretrizes e bases da Educação Nacional. Brasília, DF: MEC, 1996.

BRASIL. Instituto Nacional de Estudos e Pesquisas Educacionais Anísio Teixeira. Censo da educação superior. Brasília, DF: Inep, 2019.

CURY, Carlos Roberto Jamil. A educação básica no Brasil. Educação \& Sociedade, Campinas, v. 23, n. 80, p. 168-200, 2002. Disponível em: https://doi.org/10.1590/S0101-73302002008000010. Acesso em: 15 jan. 2021.

FARIA, Ana Amália Gomes de Barros Torres; ALMEIDA, Lenadro S. Adaptação acadêmica de estudantes do 1o ano: promovendo o sucesso e a permanência na Universidade. Revista Internacional de Educação Superior, Campinas, v. 7, e021024, 2020. DOI: 10.20396/riesup.v7i0.8659797. Disponível em: https://periodicos.sbu.unicamp.br/ojs/index.php/ riesup/article/view/8659797. Acesso em: 25 jan. 2021. 
FERRETTI, Celso João. A reforma do Ensino Médio e sua questionável concepção de qualidade da educação. Estudos Avançados, São Paulo, v. 32, n. 93, p. 25-42, 2018. Disponível em: https://doi.org/10.5935/0103-4014.20180028. Acesso em: 23 jan. 2021. FRANCO, Maria Laura Puglisi Barbosa. Análise de Conteúdo. 5. ed. Campinas: Autores Associados, 2018.

FREIRE, Paulo Ricardo. A Representação Social da docência pelos alunos do curso de Pedagogia da Faculdade de Educação da Universidade Federal do Amazonas: um diálogo com Bourdieu em um estudo do Percurso no processo de formação. 2015. Tese (Doutorado em Educação) - Programa de Pós-Graduação em Educação, Universidade Federal do Amazonas, Manaus, 2015. JARDIM, Fabiana Augusta Alves; ALMEIDA, Wilson Mesquita de. Expansão recente do ensino superior brasileiro: (novos) elos entre educação, juventudes, trabalho? Linhas Críticas, Brasília, DF, v. 22, n. 47, p. 63-85, jan./abr. 2016. Disponível em: https://doi.org/10.26512/lc.v22i47.4776. Acesso em: 15 jan. 2021.

LIMA, Fábio Souza. As raízes da Faculdade de Educação da UFAM: uma análise do contexto em que a instituição se desenvolveu (1960 a 1980). Revista Amazônida: Revista do Programa de Pós-Graduação em Educação da Universidade Federal do Amazonas, Manaus, v. 1, n. 1, p. 106-141, 2020. Disponível em: https://doi.org/10.29280/rappge.vli01.7347. Acesso em: 24 jan. 2021.

LIMA, Nara Maciel Falcão. Jovens de camadas populares na Educação Superior pública do Amazonas: acesso e permanência. 2018. Tese (Doutorado em Sociedade e Cultura na Amazônia) - Programa de Pós-Graduação em Sociedade e Cultura na Amazônia, Universidade Federal do Amazonas, Manaus, 2018.

MATTA, Karen Weizenmann da. Evasão universitária estudantil: precursores psicológicos do trancamento de matrícula por motivo de saúde mental. 2011. Dissertação (Mestrado em Psicologia Clínica e Cultura) - Programa de Pós-Graduação em Psicologia Clínica e Cultura, Universidade de Brasília, Brasília, DF, 2011.

MELO, Kesia Cristine. Escolha de curso e evasão universitária: análises a partir do Sistema de Seleção Unificada. 2017. Dissertação (Mestrado Profissional em Gestão de Processos Institucionais) - Centro de Ciências Humanas, Letras e Artes, Universidade Federal do Rio Grande do Norte, Natal, 2017.

MARCONI, Marina de Andrade; LAKATOS, Eva Maria. Fundamentos de metodologia científica. 5. ed. São Paulo: Atlas, 2003.

PICANÇO, Felícia. Juventude por cor e renda no acesso ao ensino superior. Somando desvantagens, multiplicando desigualdades? Revista Brasileira de Ciências Sociais, São Paulo, v. 30, n. 88, p. 145-179, jun. 2015.

PERETTA, Anabela Almeida Costa e Santos; OLIVEIRA, Ítalo Weiner Martins de; LIMA, Luana Mundin de. Roda de conversa sobre evasão: a psicologia escolar no ensino superior. Psicologia Escolar e Educacional, São Paulo, v. 23, p. 1-4, 2019. Disponível em: https://doi.org/10.1590/2175-35392019016484. Acesso em: 22 jan. 2021.

SEVERINO, Antonio Joaquim. Docência e pesquisa: o PIBIC e o PIBID como estratégias pedagógicas. Revista Intersaberes, Curitiba, v. 11, n. 22, p. 236-246, jan./abr. 2016. Disponível em: https://doi.org/10.22169/intersaberes. v11i22.1010. Acesso em: 25 jan. 2021.

SILVEIRA, Fernando Lang da; BARBOSA, Marcia Cristina Bernardes; SILVA, Roberto da. Exame Nacional do Ensino Médio (ENEM): uma análise crítica. Revista Brasileira de Ensino de Física, São Paulo, v. 37, n. 1, p. 1101, jan./mar. 2015. Disponível em: http://dx.doi.org/10.1590/S1806-11173710001. Acesso em: 23 jan.2021.

SPOSITO, Marilia Pontes; TARÁBOLA, Felipe de Souza. Entre luzes e sombras: o passado imediato e o futuro possível da pesquisa em juventude no Brasil. Revista Brasileira de Educação, Rio de Janeiro, v. 22, n. 71, 2017. Disponível em: https://doi.org/10.1590/s1413-24782017227146. Acesso em: 17 ago. 2020.

TARÁBOLA, Felipe de Souza. Sentidos da Participação: Considerações sobre o engajamento de jovens de camadas populares em Universidades Públicas. In: REUNIÃO NACIONAL DA ANPEd, 39., 2019, Niterói. Anais eletrônicos [...]. Niterói: Universidade Federal Fluminense, 2019. Disponível em: http://39.reuniao.anped.org.br/wp-content/uploads/ sites/3/trabalhos/4732-TEXTO_PROPOSTA_COMPLETO.pdf. Acesso em: 15 jul. 2020.

TARTUCE, Gisela Lobo B. P; NUNES, Marina M. R; ALMEIDA, Patrícia Cristina Albieri de. Alunos do ensino médio e atratividade da carreira docente no Brasil. Cadernos de Pesquisa, São Paulo, v. 40, n. 140, p. 445-477, maio/ago. 2010. Disponível em: https://doi.org/10.1590/S0100-15742010000200008. Acesso em: 12 dez. 2020.

UNIVERSIDADE FEDERAL DO AMAZONAS. Estatuto da UFAM. AMAZONAS: UFAM, 1998. Disponível em: https://edoc.ufam.edu.br/bitstream/123456789/996/1/ESTATUTO\%20DA\%20UFAM.pdf. Acesso em: 7 ago. 2020.

UNIVERSIDADE FEDERAL DO AMAZONAS. Projeto Pedagógico do Curso de Licenciatura Plena em Pedagogia versão 2019/1. Manaus: FACED, 2019. Disponível em: http://faced.sites.ufam.edu.br/images/ppc/PPC2019\%201.pdf. Acesso em: 12 jan. 2021.

UNIVERSIDADE FEDERAL DO AMAZONAS. Programação de Acolhida aos estudantes - 2020. Manaus: UFAM, 2020. Disponível em: https://drive.google.com/file/d/1OPmuNgeC6wrpXMxRipM3r5-PGobApoeB/view. Acesso em: 12 dez. 2020.

ZAGO, Nadir. Do acesso à permanência no ensino superior: percursos de estudantes universitários de camadas populares. Revista Brasileira de Educação, Rio de Janeiro, v. 11, n. 32, p. 226-370, maio/ago. 2006. Disponível em: https:// www.scielo.br/pdf/rbedu/v1ln32/a03v11n32.pdf. Acesso em: 15 jul. 2020.

Data de submissão: 29/01/2021

Data de aceite: 10/02/2021 